\title{
Modified gift box technique for acute compound posttraumatic Achilles tendon repair in young patients
}

\author{
Tushar Singhi*, Ashith Rao, Abhay Agarwal, Sunil Shetty, Prakash Samant
}

Department of Orthopedics, D Y Patil Medical College, Sector 7, Nerul, Navi Mumbai, India

Received: 03 December 2017

Revised: 04 February 2018

Accepted: 06 February 2018

\author{
*Correspondence: \\ Dr. Tushar Singhi, \\ E-mail: tusharsinghi@hotmail.com
}

Copyright: (C) the author(s), publisher and licensee Medip Academy. This is an open-access article distributed under the terms of the Creative Commons Attribution Non-Commercial License, which permits unrestricted non-commercial use, distribution, and reproduction in any medium, provided the original work is properly cited.

\begin{abstract}
Background: Treatment of Achilles tendon rupture in young active patient remains controversial. Open primary repair remains the mainstay of treatment with prolonged rehabilitation and high wound complication rate (20\%). In compound injuries it becomes the default treatment. Newer techniques are being tried to decrease re-rupture rate, decrease local complications and facilitate early rehabilitation. Modified gift box technique of open repair, which has shown higher strength of repair in in-vitro studies and good clinical results in the hands of its inventor. The aim of our study was to evaluate the clinical results of this technique in young active patients with compound Achilles tendon injury.

Methods: This is a retrospective study. The parameters recorded at follow up included general demography, ability to single toe raise (on neutral, incline, decline), toe walking for $40 \mathrm{feet}$, and pain on VAS scale. Achilles tendon total rupture score and modified Rupp score were administered.

Results: Out of the 8 patients included in the study, 7 patients had unilateral tear and 1 patient had bilateral tear. The mean age was 27 yrs (20-35) and mean duration of follow up was 17.4 months (08-24 months). Single toe raise and toe walking for $40 \mathrm{ft}$. was possible in all patients. Two patients complained of grade 2 pain on VAS Scale. The ATRS score was 97.1 (94-99) and modified Rupp score was 28.3 (26-29).

Conclusions: Modified gift box technique gives excellent results in young active patients with compound Achilles tendon injury with no re-rupture and return of pre-injury activity.
\end{abstract}

Keywords: Compound Achilles injury, Modified gift-box

\section{INTRODUCTION}

Incidence of Achilles tendon injury is about 1-2 per 10000 and it is the third most frequent tendon rupture. ${ }^{1-3}$ Non-surgical treatment leads to high incidence (10\%$30 \%$ ) of re-rupture (specially in high demand and young patients), increased tendon lengthening and reduced power. ${ }^{4-14}$ Surgical intervention has a lesser incidence of re-rupture $(<5 \%)$; therefore it is preferred in younger patients. ${ }^{7-11}$ One of the studies found a very high rate of re-rupture (17\%) in very young patients (20-30 yrs.) even after open repair. ${ }^{15}$ Open repair has higher incidence of local complications (20-30\%) like infection, delayed wound healing, sural nerve injury, deep crural flebothromboses and problems with shoe wear causing contact ulcer due to enlargement of sutured tendon. ${ }^{13,14}$

Percutaneous/limited open techniques decrease the incidence of local wound complications and have an incidence of re-rupture similar to operative repair $(10 \%){ }^{16-18,19}$ Although more research is required for a final conclusion on the same. ${ }^{16}$ Lee et al showed better 
strength with open repair compared to percutaneous repairs. $^{20}$ Open surgical repair is preferred in high demand patients like sportsmen and manual laborers. ${ }^{17,18}$ None of the studies have reported results in open Achilles tendon injury due to incision with sharp object in young patients. An open repair seems to be the most plausible treatment in this scenario.

The traditional surgical interventions used were the Krackow procedure, the Bunnell procedure and the Mac Griffith procedure. ${ }^{21,22}$ Newer techniques are being tried to decrease re-rupture rate, restore power, decrease local complications and facilitate early rehabilitation. One of these is the modified gift box technique described by Labib et al. ${ }^{23,24}$ In an in vitro study it was found to have strength, which was twice that of the traditional Krackow procedure although a meta-analysis of cadaveric studies done to find the best suturing technique was inconclusive. $^{23,25} \mathrm{We}$ have been using the gift box technique of repair as described by Labib et al for the last 2-years. ${ }^{24} \mathrm{We}$ decided to retrospectively review all repairs done with this technique in young patients $(<35$ yrs of age) with open Achilles tendon rupture, as the in vivo benefit of better suturing technique would be realized in younger patients who have higher rate of rerupture.

\section{METHODS}

Modified gift box technique was a new technique at our centre 2 years back. We started prospective data collection of these patients when the new technique was introduced. This study is a retrospective evaluation of prospectively collected data of young active patients $(<35$ years of age) with acute compound post-traumatic Achilles tendon rupture. All surgeries were done at (D Y Patil Hospital, Navi Mumbai) between 2013 to 2015.The indoor files of these patients were reviewed and data regarding general demographics (age, sex, occupation, side, mode of injury and co-morbidities), intra-operative and post-operative complications was extricated. All patients who had completed at least 12 months from the surgery were included in the study. Patients who were operated more than 4 weeks after the injury and whose age was more than 35 years were excluded from the study. The 6 months and 1 year follow up data was extricated from the records and additionally all patients were again called for a review in outpatient department.

All surgeries were either done or were supervised by a single surgeon. The surgical technique used has been well described by Labib et al Patient was taken in prone position under epidural anesthesia/general anesthesia with thigh tourniquet in place. ${ }^{21}$ The edges of the wound present due to injury were extended and the incision was carried directly to the paratenon. Limited dissection was carried just superficial to the paratenon to differentiate the layer. The paratenon was then opened and again limited dissection deep to the paratenon till the lateral edges of the tendon was done. After debriding the edges of the tendon, number 3 ethibond (ethicon, Himachal Pradesh) is passed from the cut edge to the lateral margin and Krackow stitch is taken (Figure 1). This looping is restricted to the lateral third of the tendon and at the proximal end it is passed transversely in the midsubstance from lateral to medial edge. A Krackow stitch is similarly taken on the medial margin from the transverse suture to the cut end (Figure 1). A similar stitch is then taken in the distal stump (Figure 1). Using straight needles the free suture ends are then passed across the rupture site into the opposite end of the tendon, one superficial and one deep to the transverse limb of the opposite Krackow suture (Figure 2). Suture knots are then tied proximal and distal to Krackow suture (Figure 3). Epitendinous suturing with prolene 3-0 (ethicon, Aurangabad) is then done. The paratenon is then closed with Vicryl 3-0 (ethicon, Aurangabad). Subcutaneous closure with vicryl 1-0 (Ethicon, Aurangabad) and skin with ethilon 3-0 (ethicon, Himachal Pradesh) is done. Before subcutaneous closure, the position of ankle flexion in full knee extension, which leads to no tension on the repair site, is noted.

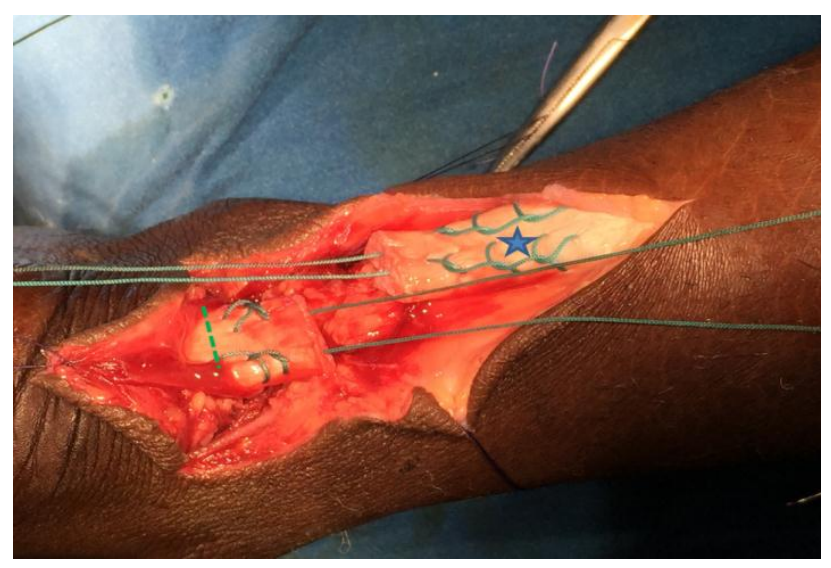

Figure 1: Showing Krackow stitches taken in proximal and distal stumps Blue star represents Krackow stitches in proximal stump Green line represents transverse suture in distal stump.

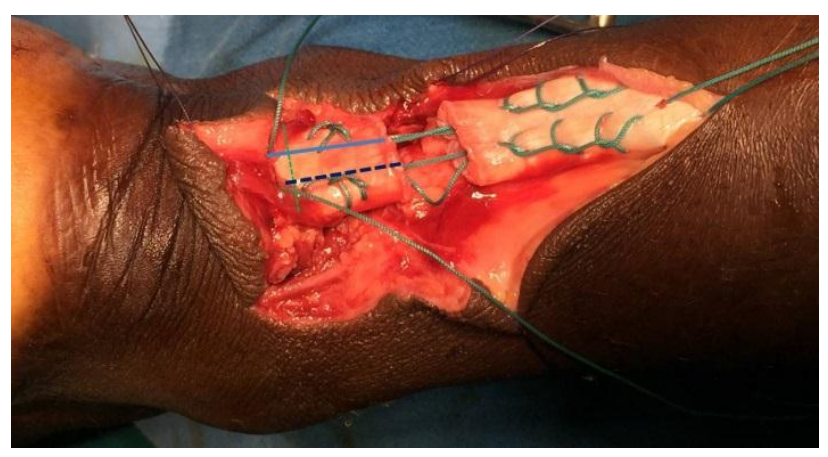

Figure 2: Free suture ends of the proximal stump passed into the distal stump green line shows the transverse suture light blue line shows proximal stump suture superficial to transverse suture dark blue line shows proximal stump suture going deep to transverse suture. 


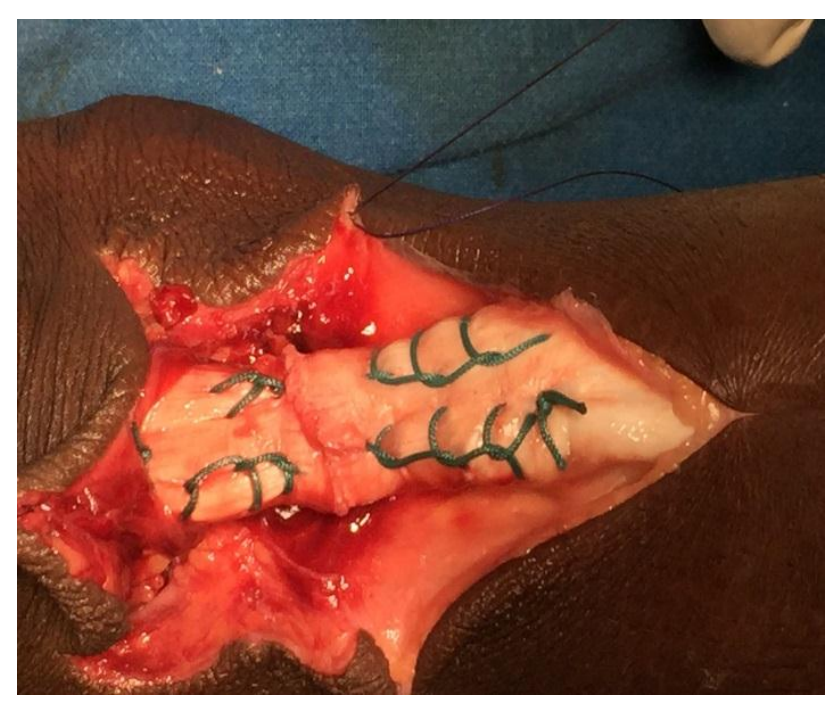

Figure 3: Completed repair.

Below knee cast was applied in the amount of plantar flexion of ankle that does not stress the repair site as noted intra-operatively. If the repair site gets stretched even with complete plantar flexion of ankle with full knee extension, an above knee cast with knee in 20degree flexion was given. Suture removal was done at 2 weeks and below knee cast was continued for another 4 weeks. Non-weight bearing status was maintained for a total of 6 weeks. Partial Weight bearing was then started in a below knee cast in neutral position of ankle for another 4 weeks. Cast removal was done 10 weeks from surgery and weight-bearing ambulation to comfort was allowed. Return to high impact activities was allowed 6 months from the surgery.

The parameters recorded for all patients at follow up as per our protocol included Thompson's test, pain on VAS scale, range of motion of ankle, problems with shoe wear, neurological deficit in foot, and calf diameter at maximal girth of calf. ${ }^{26}$ Single leg toe raising (on neutral, incline and decline) and toe walking for 40 feet were taken as parameters of strength recovery at 6 months, 1 year and at latest follow up. ${ }^{27}$ Achilles tendon total rupture score (ATRC) and modified Rupp score were administered at 6 months, 1 year and at latest follow-up. ${ }^{28,29}$ The time of return to pre-injury occupation from repair was noted.

\section{RESULTS}

Fifteen compound tendo-Achilles ruptures were operated between 2013-2015. Out of 15 patients, 7 patients were excluded from the study. Out of the 7 excluded patients, 2 patients were operated 5 weeks after injury, 2 patients were operated with a different surgical technique and 3 patients were above 35 years of age. Out of 8 patients included in the study, 7 patients had unilateral tear and 1 patient had bilateral tear. The general demographics of patients is listed in Table 1.The mean age was 27 yrs (2035). There were 7 males and 1 female. The mode of injury was injury from sharp object in all patients. The mean duration of follow up was 17.4 months (08-24 months).

Table 1: General demographics, mode of injury \& comorbidities.

\begin{tabular}{|lll|}
\hline Total number of patients & $\mathbf{8}$ \\
\hline Age in years & $27(20-35)$ & \\
\hline \multirow{2}{*}{ Sex } & Male & 7 \\
\hline \multirow{3}{*}{ Mode of injury } & Female & 1 \\
\hline \multirow{5}{*}{ Co-morbidities } & $\begin{array}{l}\text { Injury from } \\
\text { sharp object }\end{array}$ & 8 \\
\cline { 2 - 3 } & Fall & 0 \\
\hline Diabetes mellitus & 0 \\
\hline Renal diseases & 0 \\
\hline Autoimmune & 0 \\
\hline Alcoholism & $\begin{array}{l}\text { disease } \\
\text { Tobacco chewing }\end{array}$ & 0 \\
\hline
\end{tabular}

Table 2 lists the results at latest follow-up. At the latest follow-up, no patient had a re rupture as judged by the Thompson test. The mean dorsiflexion was 12.2 (08-15) degrees and plantar flexion was 31.8 (30-35) degrees. No patient had hyper-dorsiflexion. Single leg toe raise (in neutral, incline, decline) was possible in all patients (Figure 4). Toe walking for $40 \mathrm{ft}$. was possible in all patients. The average calf diameter was $0.78 \mathrm{~cm}$ less then the opposite side in the 7 unilateral patients. At final follow-up, the mean ATRC score was 97.1 (94-99) and modified Rupp Score was 28.3 (26-29) (Table 3).

The complications during the study period are listed in Table 4. Three patients complained of pain over the repaired area, which was graded 2 on the VAS scale. One patient had skin necrosis $2 \times 4 \mathrm{~cm}$ over the tendon, which required split skin grafting at 3 weeks after primary surgery (Figure 5). This complication did not affect his post-operative rehabilitation or his post-operative recorded parameters. One patient with bilateral surgery had breakdown of skin over the suture knot tied on the distal stump 4 months after primary surgery on one side (Figure 6a). Removal of the knot was done under local anesthesia. The wound healed (Figure 6b) but the patient presented 2 months after knot removal with fluctuant swelling over the lower $25 \%$ of the tendon. MRI showed diffuse swelling around the tendon with a small collection. The patient was started on intravenous antibiotics, as the skin was not conducive for surgery. After two weeks of antibiotics, the tendon was explored which revealed granulation tissue around the nonabsorbable Ethibond suture (Figure 6d). The suture was completely removed along with the granulation tissue and patient was kept in a below knee cast for next 3 weeks. Intravenous antibiotics for 5 days were administered. There were no issues after that and the patient gained full power at final follow-up. 
Table 2: Postoperative physical examination parameters.

\begin{tabular}{|c|c|c|}
\hline Total number of patients (no of tears) & $8(9)$ & \\
\hline Duration of follow-up in months average (range) & $17.4(12-24)$ & \\
\hline \multirow{2}{*}{ Thompson's test } & Positive & 0 \\
\hline & Negative & 9 \\
\hline \multirow{2}{*}{ Range of motion mean (range) } & Dorsiflexion & $12.2(08-15)$ \\
\hline & Plantarflexion & $31.8(30-35)$ \\
\hline \multirow{3}{*}{ Number of repairs with single toe raising from initial position of foot } & In neutral & 9 \\
\hline & In incline & 9 \\
\hline & In decline & 9 \\
\hline Number of repairs who could Toe walk for $40 \mathrm{ft}$ & 9 & \\
\hline \multirow{2}{*}{$\begin{array}{l}\text { Difference in calf diameter between operated and normal at last follow- } \\
\text { up }\end{array}$} & Unilateral ruptures- 7 & $0.78 \mathrm{~cm}$ \\
\hline & Bilateral ruptures - 1 & - \\
\hline Number of repairs with return to pre-operative activity & & 9 \\
\hline
\end{tabular}

Table 3: Postoperative assesment scores.

\begin{tabular}{|lllllll|}
$\begin{array}{l}\text { Total number } \\
\text { of patients (no } \\
\text { of tears) }\end{array}$ & $\begin{array}{l}\text { ATRS score } \\
\text { A verage (Range) }\end{array}$ & & \multicolumn{2}{l}{$\begin{array}{l}\text { Mod. Rupp score } \\
\text { Average (Range) }\end{array}$} \\
\hline \multirow{8}{*}{$\mathbf{8}(\mathbf{9})$} & 6 months & 1 year & $\begin{array}{l}\text { At Last } \\
\text { follow-up }\end{array}$ & 6 months & 1 year & At Last follow-up \\
& $\begin{array}{l}90.1 \\
(86-93)\end{array}$ & $\begin{array}{l}94.7 \\
(91-97)\end{array}$ & $\begin{array}{l}97.1 \\
(94-99)\end{array}$ & $\begin{array}{l}23.7 \\
(16-28)\end{array}$ & $\begin{array}{l}26.5 \\
(19-30)\end{array}$ & 28.3 \\
\end{tabular}

Histopathological examination of granulation tissue revealed inflammatory infiltrate with no foreign body giant cells. Two patients had difficulty in wearing shoes with counter, secondary to increase in girth of tendon at the repair site and also due to scar hypertrophy. Two patients had sural nerve injury pre-operatively which was not repaired because of skin healing concerns. This was responsible for tingling and numbness and some pain over the repair site and over the lateral aspect of tendon bulge.

As all our patients were young and were involved in strenuous activities. Full activity was allowed at 6 months when they were able to carry on with their activities. There was no patient who could not return to his original job post-surgery. The average time of return to pre-injury work was 6 months and 23 days. If we exclude the patient with breakdown of skin over distal knot the return time was 6 months.

Table 4: Complications of Achilles tendon repair.

\begin{tabular}{|ll|}
\hline Complication & Number of repairs \\
\hline Infection & 1 \\
\hline $\begin{array}{l}\text { Wound dehiscence/wound } \\
\text { complication }\end{array}$ & 1 \\
\hline Sural nerve injury & 2 \\
\hline DVT & 0 \\
\hline Problem with shoe wear & 2 \\
\hline Re-rupture & 0 \\
\hline
\end{tabular}

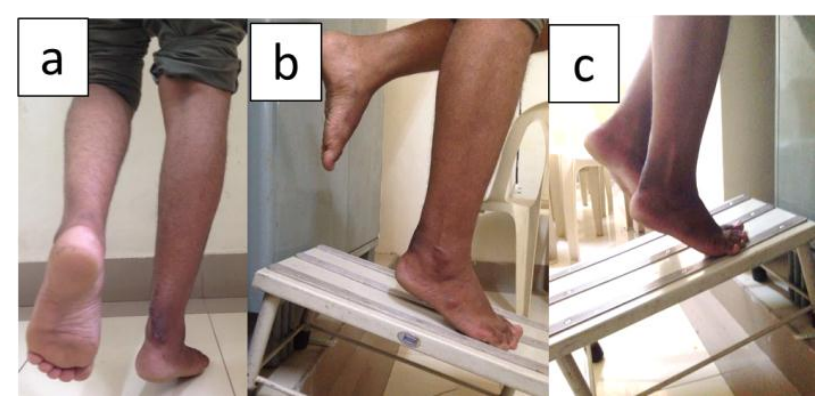

Figure 4: (a) Single leg toe rise in neutral, (b) decline and (c) incline.

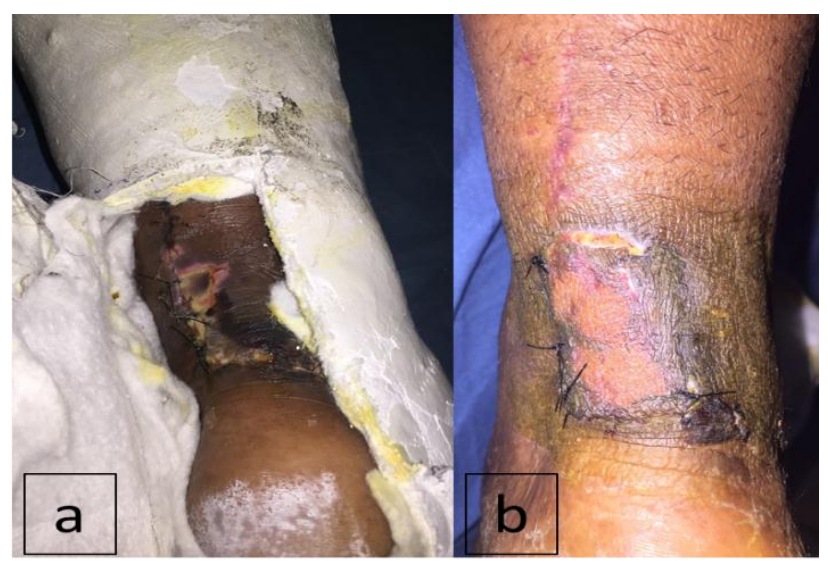

Figure 5: (a) Skin necrosis post-operatively. (b) healed well with split skin grafting 


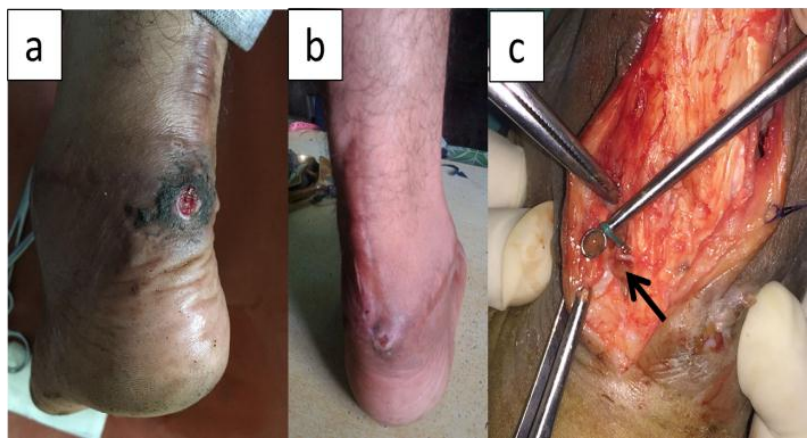

Figure 6: (a) Skin necrosis over distal knot (b) healing after knot removal (c) suture material during revision surgery with granulation tissue around (black arrow).

\section{DISCUSSION}

The aim of our study was to find out the result of Achilles tendon repair with gift box technique in young patients with open rupture of Achilles tendon due to injury by sharp object.

There is a relative paucity of literature regarding compound Achilles tendon injuries and we could only find two studies, one by Chaterjee et al of 18 cases following a unique injury mechanism of fall in the lavatory pan and the other by Awee et al of 52 cases following varied mechanism of injury predominantly Road traffic accidents. ${ }^{29,30}$ Repair in these cases involves due consideration of the overlying soft tissue for healing capacity as the wound will have to be extended during surgery. Chatterjee et al did an augmented repair with regional flaps in 4 cases out of 18 repairs due to the presence of skin laceration. ${ }^{30}$ They reported a skin edge necrosis of $16 \%$ which was treated with dressing and antibiotics. Awee et al did a primary repair only in $53.9 \%$ cases while a secondary repair was done in $25 \%$ cases and an augmented repair \pm flaps in $21.2 \%$ cases. $^{29} 48 \%$ of the patients in Awee's series involved a road traffic accident with major lacerations necessitating a secondary/ augmented repair. ${ }^{29}$ Awee's series reported a flap tip necrosis of $4 \%$ and a wound dehiscence of $2 \%{ }^{29}$ The mechanism of injury in our cases was by a sharp object, so all cases in our series were amenable to primary repair. One patient $(11 \%)$ had a minor skin healing issue postoperatively requiring grafting. As we had complication related to wound healing only in one patient out of eight, we would infer that TA repair in sharp cut compound injuries can be done acutely. Skin healing issues are similar to what we get when we do open repair after a closed rupture. ${ }^{13,14}$

Another consideration is the amount of contamination of the wound during injury and the duration of presentation post injury. One patient in our series had wound breakdown at 4 months. We think this patient had a prominent distal knot, which because of rubbing with the counter of the shoe lead to skin breakdown and this further lead to infection around the suture. Complete removal of the suture lead to resolution of the problem. Awee et al reported an infection rate of 5\% and all were treated with dressings and antibiotics, although the kind of suture material used was not described in the article. ${ }^{29}$ Chatterjee et al, in their series of 18 cases of compound tendoachilles injury, reported sinuses and granuloma formation in 11 of 12 patients in whom prolene was used for the repair and none in the cases in which pull out stainless steel wire was used. ${ }^{30}$ Out of these 11 patients, 5 patients responded to antibiotics only but the other 6 patients required repeat surgery with removal of the prolene. We had only one case of sinus formation in eight repairs compared to 11 out of 12 in Chatterjee et al series. $^{30}$ This may be because of lower level of contamination in our series as the mode of injury in our cases was different. Most of our patients (7/8) were having a clean wound and were operated within $24 \mathrm{hrs}$. One inference can be drawn out of treatment of this case along with the observation in Chatterjee et al series is that whenever such repairs present with a draining sinus or granuloma formation after complete healing of the primary incision, suture removal is the choice of treatment. $^{30}$

No re-rupture was reported in Chaterjee's and Awee's study. ${ }^{29,30}$ In our study, there was no re-rupture during the study period, although 3 patients complained of pain graded as 2 on VAS scale at the repair site after exertion. All these patients did not have any functional restriction due to this pain. We are still following these patients to see if this pain is a precursor to a re-rupture, but currently we are not able to give any explanation for this pain. Two of these patients also had an injured sural nerve, which was not repaired. Repair would have entailed further dissection in an already damaged area risking skin necrosis. Our study is in confirmation with other studies, which report low re-rupture rates with an open repair. ${ }^{7-11}$

Young patients are reported to have a higher rate of rerupture probably because of increased indulgence in sports activities or in heavy labor. ${ }^{15}$ All of our patients were laborers involved in heavy labor at construction sites or factories. The post-operative loading of the Achilles tendon in our patients is not as much as in sports injuries but is substantial. All of them required a strong tendon for their livelihood. After the surgery, all patients were able to return to their pre-injury livelihood. This suggested that the strength of repair and the range of motion of the ankle were adequate for doing these activities. It has been the observation in many previous studies that although there is no re-rupture, the plantar flexion strength does not become normal. ${ }^{10}$ Although no dynamometer was used in our study, single leg-raise on decline and toe walking for $40 \mathrm{ft}$ were used as parameters of strength testing. It was possible to do both in all patients confirming good strength recovery at final follow up. We would recommend Labib's technique for all young patients with an Achilles rupture, as we did not have any re-rupture and the recovery of plantar flexion strength was excellent. ${ }^{21}$ 


\section{Limitations of the study}

1) It was a retrospective evaluation of prospectively collected data. A prospective randomized study in young patients comparing Labib's technique with other suturing techniques would have brought out the differences in invivo performance with each of these suturing techniques.

2) The rehabilitation protocol followed in our study was conservative and many authors have suggested that early rehabilitation and weight bearing leads to better maturation of collagen with enhanced strength. ${ }^{32}$ As Labib's technique is reported to have good repair strength in cadaver studies, an early rehabilitation protocol would have tested its in vivo performance as well. We did not have any restriction of ankle ROM or decreased strength at final follow up, so the results with this protocol were good. An early rehabilitation protocol would have decreased the time from injury to return to work.

\section{CONCLUSION}

Repair of open Achilles tendon tear in young active patients by gift box technique has given excellent result with good power, no re-rupture and acceptable wound healing issues. All patients were able to return to their preinjury activity levels. We recommend this technique for all young patients who are involved in high impact activities.

\section{Funding: No funding sources}

Conflict of interest: None declared

Ethical approval: The study was approved by the institutional ethics committee

\section{REFERENCES}

1. Leppilahti J, Puranen J, Orava S. Incidence of Achilles tendon rupture. Acta Orthop Scand. 1996;67(3):277-9.

2. Maffulli N, Waterston SW, Squair J, Reaper J, Douglas A. Changing incidence of Achilles tendon rupture in Scotland: a 15-year study. Clin J Sport Med. 1999;9(3):157-60.

3. Nyyssonen T, Luthje P, Kroger H. The increasing incidence and difference in sex distribution of Achilles tendon rupture in Finland in 1987-1999. Scand J Surg. 2008;97:272-5.

4. Wills CA, Washburn S, Caiozzo V, Prietto CA. Achilles tendon rupture: a review of the literature comparing surgical versus nonsurgical treatment. Clin Orthop. 1986;207:156-63.

5. Popovic N, Lemaire R, Diagnosis and treatment of acute ruptures of the Achilles tendon. Current concepts review. Acta Orthopaedica Belgica. 1999;65:458-71.

6. Carden DG, Noble J, Chalmers J, Lunn P, Ellis J. Rupture of the calcaneal tendon. The early and late management. J Bone Joint Surg. 1987;69:416-20.
7. Cetti R, Christensen SE, Ejsted R, Jensen NM, Jorgensen $\mathrm{U}$. Operative versus nonoperative treatment of Achilles tendon rupture. A prospective randomized study and review of the literature. Am J Sports Med. 1993;21:791-9.

8. Kevin Willits K, Amendola A, Bryant D, Mohtadi NG, Robert Giffin J, Fowler P, et al. Operative versus Nonoperative Treatment of Acute Achilles Tendon Ruptures. J Bone Joint Surg Am. 2010;92:2767-75.

9. Mullaney MJ, McHugh MP, Tyler TF, Nicholas SJ, Lee SJ. Weakness in End-Range Plantar Flexion After Achilles Tendon Repair. Am J Sports Med. 2006;34:1120.

10. Möller M, Movin T, Granhed H, Lind K, Faxén E, Karlsson J. Acute rupture of tendon-Achilles: A prospective randomized study of comparison between surgical and non-surgical Treatment. J Bone Joint Surg Br. 2001;83(6):843-8.

11. Nistor L. Surgical and non-surgical treatment of Achilles tendon rupture. A prospective randomized study. J Bone Joint Surg Am. 1981;63:394-9.

12. han RJ, Fick D, Keogh A, Crawford J, Brammar T, Parker M. Treatment of Acute Achilles Tendon Ruptures. A meta-analysis of randomized, controlled trials. J Bone Joint Surg Am. 2005;87:2202-10.

13. Soroceanu A, Sidhwa F, Aarabi S, Kaufman A, Glazebrook M. Surgical Versus Nonsurgical Treatment of Acute Achilles Tendon Rupture A Meta-Analysis of Randomized Trials. J Bone Joint Surg Am. 2012;94:2136-43

14. Rettig AC, Liotta FJ, Klootwyk TE, Porter DA, Mieling P. Potential risk of re-rupture in primary Achilles tendon repair in athletes younger than 30 years of age. Am J Sports Med. 2005;33(1):119-23.

15. Jones MP, Khan RJ, Carey Smith RL. Interventions for Treating Acute Achilles Tendon Rupture: Key Findings from a Recent Cochrane Review. J Bone Joint Surg Am. 2012;94:88.

16. Karabinas PK, Benetos IS, LampropoulouAdamidou K, Romoudis P, Mavrogenis AF, Vlamis J. Percutaneous versus open repair of acute Achilles tendon ruptures. Eur J Orthop Surg Traumatol. 2014;24(4):607-613.

17. Deangelis JP, Wilson KM, Cox CL, Diamond AB, Thomson AB. Achilles tendon rupture in athletes. J Surg Orthop Adv. 2009;18(3):115-21.

18. Clanton TO, Haytmanek CT, Williams BT, Civitarese DM, Turnbull TL, Massey MB, et al. A Biomechanical Comparison of an Open Repair and 3 Minimally Invasive Percutaneous Achilles Tendon Repair Techniques During a Simulated, Progressive Rehabilitation Protocol. Am J Sports Med. 2015;43:1957-64

19. Lee SJ, Sileo MJ, Kremenic IJ, Orishimo K, BenAvi S, Nicholas SJ, McHugh M. Cyclic loading of 3 Achilles tendon repairs simulating early postoperative forces. American $\mathrm{J}$ Sports Med. 2009;37(4):786-90. 
20. Krackow KA, Thomas SC, Jones LC. Ligamenttendon fixation: analysis of a new stitch and comparison with standard techniques. Orthopedics. 1988;11:909-17.

21. Ma GW, Griffith TG. Percutaneous repair of acute closed ruptured Achilles tendon: a new technique. Clin Orthop. 1977;128:247-55.

22. Labib SA, Rolf R, Dacus R, Hutton WC. The "Giftbox" Repair of the Achilles Tendon: A Modification of the Krackow Technique. Foot Ankle Int. 2009;30:410-4.

23. Labib SA, Edward Hoffler II C, Shah JN, Rolf RH, Tingan A. The Gift Box Open Achilles Tendon Repair Method: A Retrospective Clinical Series. J Foot Ankle Surg. 2016;55(1):39-44.

24. Sadoghi P, Rosso C, Valderrabano V, Leithner A, Vavken P. Initial Achilles tendon repair strengthsynthesized biomechanical data from 196 cadaver repairs. International Orthopaedics (SICOT). 2012;36:1947-51.

25. Thompson TC, Doherty JH. Spontaneous rupture of tendon of Achilles: a new clinical diagnostic test. J Trauma Acute Care Surg. 1962;2(2):126-9.

26. Mullaney MJ, McHugh MP, Tyler TF, Nicholas SJ, Lee SJ. Weakness in End-Range Plantar Flexion After Achilles Tendon Repair. Am J Sports Med. 2006;34:1120-5.

27. Nilsson-Helander K, Thomeé R, GrävareSilbernagel K, Thomeé P, Faxén E, Eriksson BI, et al. The Achilles Tendon Total Rupture Score (ATRS): Development and Validation. Am J Sports Med. 2007;35:421-6.

28. Kerkhoffs GM, Strijs PA, Raaymakers EL, Marti RK. Functional treatment after surgical repair of acute Achilles tendon rupture: Wrap vs walking cast. Arch Orthop Trauma Surg. 2002;122:102-5.

29. Awe Oo, Esezobor Ee, Aigbonoga Qo. Experience with managing open Achilles tendon injuries in a tertiary hospital in Southern Nigeria. J West African Coll Surg. 2015;5(4):30-40.

30. Chatterjee SS, Sarkar A, Misra A. Management of acute open tendo-achilles injuries in Indian lavatory pans. Indian J Plast Surg. 2006;39(1):29-33.

31. Maffulli N, Tallon C, Wong J, Lim KP, Bleakney R. Early weightbearing and ankle mobilization after open repair of acute midsubstance tears of the Achilles tendon. Am J Sports Med. 2003;31(5):692700 .

32. Costa ML, MacMillan K, Halliday D, Chester R, Shepstone L, Robinson AH, et al. Randomised controlled trials of immediate weight-bearing mobilization for rupture of the tendo-Achilles. J Bone Joint Surg Br. 2006;88(1):69-77.

Cite this article as: Singhi T, Rao S, Agarwal A, Shetty S, Samant P. Modified gift box technique for acute compound posttraumatic Achilles tendon repair in young patients. Int J Res Orthop 2018;4:302-8. 